\title{
Understanding the Reactivity of C-Cyclopropyl-N-Methylnitrone Participating in [3+2] Cycloaddition Reactions Towards Styrene with a Molecular Electron Density Theory Perspective
}

\author{
Haydar A. Mohammad-Salim \\ Department of Chemistry, University of Zakho, Duhok, Iraq. \\ *Corresponding author: Haydar A. Mohammad-Salim, email: Hayder.salim@uoz.edu.krd
}

Received August 30 ${ }^{\text {th }}$, 2020; Accepted November 30 $0^{\text {th }}, 2020$.

DOI: http://dx.doi.org/10.29356/jmcs.v65i1.1437

\begin{abstract}
The [3+2] cycloaddition (32CA) reactions of C-cyclopropyl-N-methylnitrone 1 with styrene 2 have been studied within molecular electron density theory (MEDT) at the B3LYP/6-311++G(d,p) level of theory. These zwitterionic type 32CA reactions occur through a one-step mechanism. The 32CA reactions undergo four stereo- and regioisomeric reaction paths to form four different products, $\mathbf{3}, \mathbf{4 , 5}$ and $\mathbf{6}$. Analysis of the conceptual density functional theory (CDFT) indices predict the global electronic flux from the strong nucleophilic nitrone 1 to the styrene 2. These 32CA reactions are endergonic with reactions Gibbs free energies between 2.83 and $7.39 \mathrm{kcal}_{\mathrm{mol}}^{-1}$ in the gas phase. The 32CA reaction leading to the formation of cycloadduct $\mathbf{3}$ presents the lowest activation enthalpy than the other paths due to a slightly increase in polar character evident from the global electron density transfer (GEDT) at the transition states and along the reaction path. The bonding evolution theory (BET) study suggests that these 32CA reactions occur through the coupling of pseudoradical centers and the formation of new $\mathrm{C}-\mathrm{C}$ and $\mathrm{C}-\mathrm{O}$ covalent bonds has not been started in the transition states.

Keywords: Electron localization function, isoxazolidines, [3+2] cycloaddition reactions, molecular electron density theory.

Resumen. Las reacciones de cicloadición [3+2], denotadas como 32CA, entre C-ciclopropil-N-metilnitrona 1 y estireno 2 se estudian mediante la teoría de la densidad electrónica molecular (MEDT) utilizando el nivel de teoría B3LYP/6-311++G(d,p). Estas reacciones 32CA de tipo zwiteriónicas se llevan por un mecanimso de un paso. Las reacciones 32CA ocurren a través de cuatro caminos estereo y regioisoméricos de reacción formando cuatro diferentes productos $3, \mathbf{4}, 5$ y $\mathbf{6}$. El análisis de los índices de la teoría conceptual de funcionales de la densidad (CDFT) predice un flujo electrónico global de la nitrona 1, un nucleófilo fuerte, al estireno 2. En fase gaseosa, estas reacciones 32CA son endergónicas con energías libres de Gibbs entre 2.83 y $7.39 \mathrm{kcal}^{\mathrm{mol}}{ }^{-1}$. La reacción 32CA que lleva a la formación del cicloaducto 3 tiene la menor entalpía de activación de las cuatro consideradas y esto se debe a un ligero incremento en el carácter polar que es evidente con la transferencia global de densidad electrónica (GEDT) en los estados de transición y a lo largo de los caminos de reacción. El esudio mediante la teoría de evolución del enlace (BET) sugiere que estas reacciones 32CA ocurren mediante el acoplamiento de centros pseudoradicales y la formación de nuevos enlaces covalentes $\mathrm{C}$-C y $\mathrm{C}$-O que no han iniciado en el estado de transición

Palabras clave: Función de localización electronica, isoxazolidinas, reacciones de cicloadición [3+2], teoría de la densidad electrónica molecular.
\end{abstract}




\section{Introduction}

Computational studies on cycloaddition reactions, in recent years, have been the subject of a number of researches due to their wide applications on synthetic organic compounds [1-5]. Among cycloadditions, [3+2] cycloaddition reactions (32CAs) represent versatile process for the synthesis of a system with five membered ring and a large variety of heterocyclic compounds can be synthesized relying on the choice of the three-atom-component (TAC) and the alkenes derivative [6-9]. The 32CA reaction of nitrones as a TCA to alkenes has been widely used during recent two decades as a key step for the construction of various heterocycles that are of great interest in pharmaceutical and medicinal chemistry [10-13].

In the past few years, the advent of computational chemistry has gradually attracted theoretical chemists to analyze the reactivity and selectivity of organic molecules. A new theoretical outlook for organic reactions was proposed by Domingo in 2016 named the molecular electron density theory (MEDT) after interpretation of a vast array of organic reactivity, majority of them dedicated to Diels-Alder and 32CA reactions [14-18]. This theory analyzes the changes in electron density to study the molecular reactivity and has been successfully applied for several 32CA reactions since last four years.

Various DFT studies carried out within the MEDT devoted to the TACs reactivity participating in 32CAs have allowed establishing a useful classification of 32CAs relying on the electronic structure and the TAC behavior into zwitterionic-type (zw-type), carbenoid-type and pseudodiradical-type reactions [19-21]. The feasibility of the $z w$-type reactions relies on the polar character of the 32CAs, i.e. the electrophilic character of the nitrones and the nucleophilic character of the alkenes, or vice versa. Nitrones, in general, are good nucleophiles, which make them able to react with electron-deficient alkenes [22].

In this work, a MEDT study at B3LYP/6-311++G(d,p) level of theory is presented for the synthesis of isoxazolidines from 32CA reaction of C-cyclopropyl-N-methylnitrone 1 with styrene 2 (Scheme 1), experimentally reported by Bimanand and Houk using chloroform as a solvent [23]. Herein, we studied the analysis of the reactivity indices derived from conceptual DFT for the reagents, the thermodynamic parameters of the 32CA of the nitrone 1 and styrene 2, and the electron localization function (ELF) topological analysis for understanding the bonding changes.

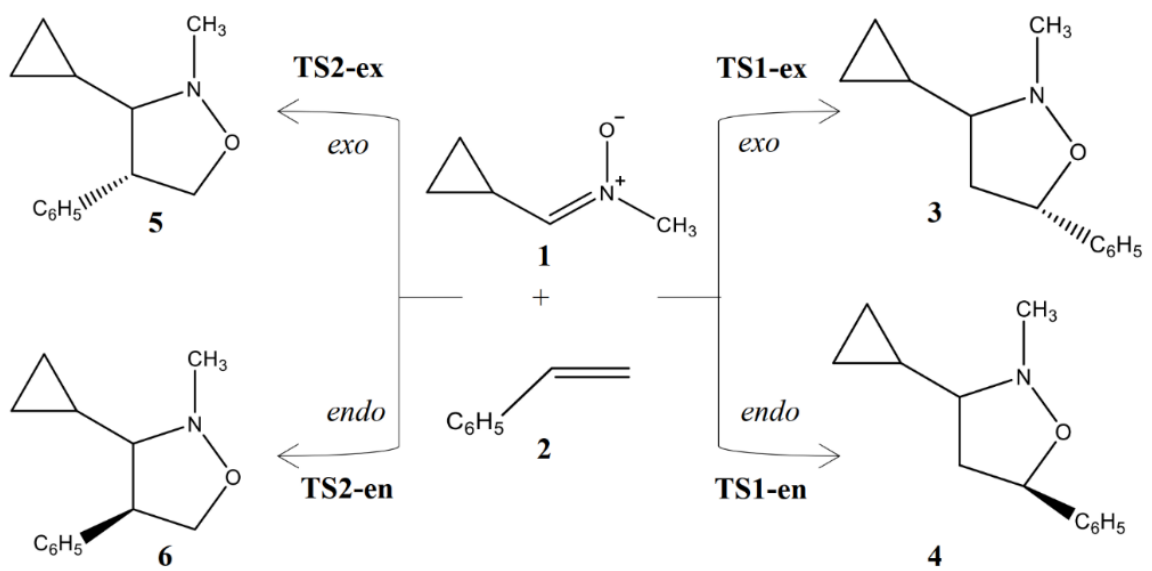

Scheme 1. Four competitive reaction paths associated to the 32CA reactions of C-cyclopropyl-N-methylnitrone 1 with styrene 2.

\section{Computational methods}

All calculations were done using the Gaussian 16 package [24]. The DFT method with B3LYP functional has been proven to be a suitable method for the study of cycloaddition reactions and is employed in 
this study [25-27]. B3LYP is used throughout in combination with the $6-311 \mathrm{G}++(\mathrm{d}, \mathrm{p})$ basis set $[28,29]$. The solute-solvent interactions have been considered using the sophisticated polarizable continuum model (PCM)[30]. The investigated solvent was chloroform.

Frequency calculations were performed for the optimized geometries to ensure that a transition state has only one imaginary frequency and that a local minimum has no imaginary frequencies. Intrinsic reaction coordinate (IRC) computations were carried out to verify that the minimum energy reaction pathway via a transition state connects with the corresponding reactants and products using the second order GonzálezSchlegel integration method [31].

The Global Electron Density Transfer (GEDT) of the reaction is calculated by the sum of the natural atomic charges, obtained through natural population analysis (NPA), of all the atoms belonging to each framework at the transition states [32]. The enthalpies, Gibbs free energies and entropies were calculated in the gas phase and in chloroform as a solvent with the standard statistical thermodynamics at $298.15 \mathrm{~K}$ and $1 \mathrm{~atm}$. The Chimera 1.14 software was used as a graphical interface [33].

The chemical hardness $(\eta)$ and the electronic chemical potential $(\mu)$ quantities may be approached in terms of the one electron energies of Highest Occupied Molecular Orbital (HOMO) and Lowest Unoccupied Molecular Orbital (LUMO), $\varepsilon_{\text {Hомо }}$ and $\varepsilon_{\text {LUMO, }}$ as in Equation 1 and 2, respectively [34, 35]. The global electrophilicity index $(\omega)$ is calculated using Equation 3 [36]. The relative nucleophilicity index $(\mathrm{N})$ is obtained based on the energies of HOMO within the scheme of Kohn-Sham [37]. This quantity can be defined as in Equation 4. The tetracyanoethylene (TCE) is chosen as reference due to its lowest HOMO energy [38].

$$
\begin{aligned}
& \eta=\left(\varepsilon_{\text {LUMO }}-\varepsilon_{\text {HOMO }}\right) \\
& \mu=\frac{\varepsilon_{\text {HOMO }}+\varepsilon_{\text {LUMO }}}{2} \\
& \omega=\frac{\mu^{2}}{2 \eta} \\
& N=E_{\text {HOMO }(N u)}-E_{\text {HOMO }(T C E)}
\end{aligned}
$$

\section{Results and discussion}

\section{ELF topological analysis of C-cyclopropyl-N-methylnitrone 1 with styrene 2}

The ELF establishes a straightforward quantitative connection between the electron density distribution and the chemical structure [39, 40]. Herein, the reactivity of C-cyclopropyl-N-methylnitrone 1 in $32 \mathrm{CA}$ reactions is studied from the ELF topological analysis. Additionally, the ELF of styrene 2 was also examined. The most significant valence basin populations are listed in Table 1, while the ELF localization domains of the reagents are given in Fig. 1.

The ELF topology of C-cyclopropyl-N-methylnitrone 1 shows the presence of two V(O1) and $\mathrm{V}^{\prime}(\mathrm{O} 1)$ monosynaptic basins having a total population of $5.92 \mathrm{e}$, a V(N2,O1) disynaptic basin and a $\mathrm{V}(\mathrm{N} 2, \mathrm{C} 3)$ disynaptic basin integrating population of $1.39 \mathrm{e}$ and $3.88 \mathrm{e}$, respectively. The $\mathrm{V}(\mathrm{O} 1)$ and $\mathrm{V}^{\prime}(\mathrm{O} 1)$ monosynaptic basins represent the non-bonding electron density of the $\mathrm{O} 1$ oxygen lone pairs. The $\mathrm{V}(\mathrm{N} 2, \mathrm{C} 3)$ disynaptic basins can be associated with the underpopulated $\mathrm{N} 2-\mathrm{C} 3$ double bond, while $\mathrm{V}(\mathrm{N} 2, \mathrm{O} 1)$ disynaptic basin is associated with underpopulated N2-O1 single bond. Thus, C-cyclopropyl-N-methylnitrone $\mathbf{1}$ can be classified as $z w$-type 
TAC due to the absence of carbenoid or pseudoradical centers [41-44]. This suggests participation of nitrone 1 in zw-type 32CA reactions associated with high activation energies [44].
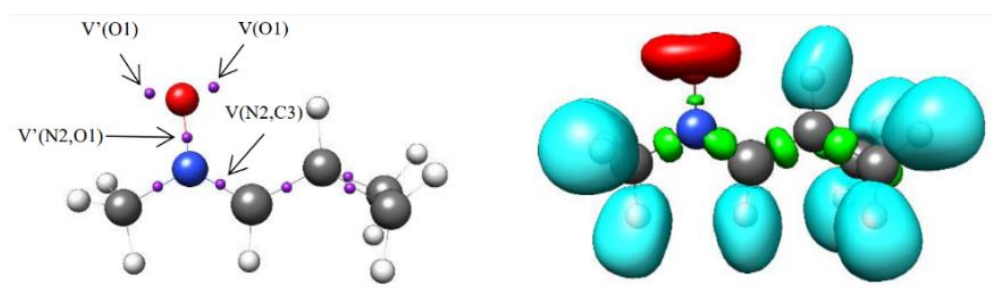

1
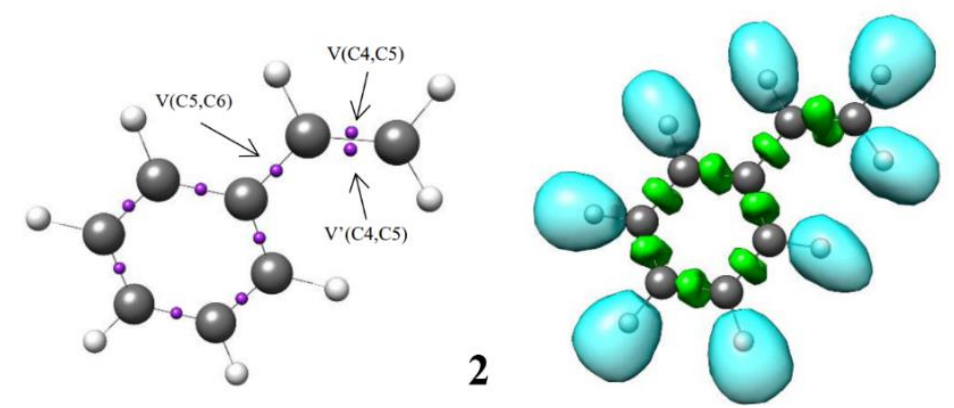

Fig. 1. B3LYP/6-311++G(d,p) calculated ELF localisation domains represented at an isosurface value of ELF $=0.80$ of C-cyclopropyl-N-methylnitrone $\mathbf{1}$ and styrene $\mathbf{2}$.

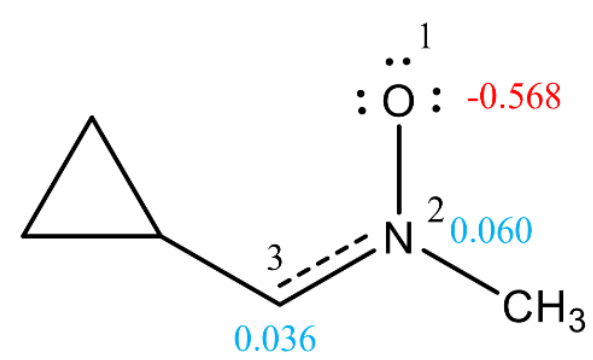

1

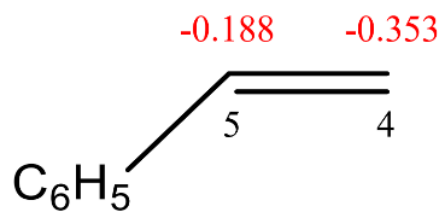

2

Fig. 2. B3LYP/6-311++G(d,p) calculated natural atomic charges, in average number of electrons e, of nitrone $\mathbf{1}$ and styrene 2. Negative charges are colored in red, and positive charges in blue.

After establishing the bonding pattern of the reagents, the atomic charge distribution of nitrone $\mathbf{1}$ and styrene 2 was analyzed through NPA (Fig. 2). O1 oxygen atom of nitrone 1 is negatively charged ( -0.568 e). C 3 carbon shows charge of $0.036 \mathrm{e}$, while N2 nitrogen is positively charged $(0.060 \mathrm{e})$. This suggests charge separation in the nitrone although differing from the charges expected by the Lewis's bonding model. Although nitrone $\mathbf{1}$ is classified as a "zwitterionic" TAC from ELF study, this terminology is not synonymous to the dipolar electronic structure of the nitrones. Instead, it indicates the specific bonding pattern (considering no charges) of the resonance Lewis structure represented by Huisgen for "1,3-dipoles" [21]. 
Table 1. B3LYP/6-311G++(d,p) calculated most significant ELF valence basin populations at C-cyclopropyl$\mathrm{N}$-methylnitrone $\mathbf{1}$ and styrene $\mathbf{2}$. ELF valence basin populations are given in average number of electrons, e.

\begin{tabular}{|c|c|c|}
\hline & $\mathbf{1}$ & $\mathbf{2}$ \\
\hline $\mathrm{V}(\mathrm{O} 1)$ & 3.03 & - \\
\hline $\mathrm{V}^{\prime}(\mathrm{O} 1)$ & 2.89 & - \\
\hline $\mathrm{V}(\mathrm{N} 2, \mathrm{O} 1)$ & 1.39 & - \\
\hline $\mathrm{V}^{\prime}(\mathrm{N} 2, \mathrm{C} 3)$ & 3.88 & - \\
\hline $\mathrm{V}(\mathrm{C} 4, \mathrm{C} 5)$ & - & 1.68 \\
\hline $\mathrm{V}^{\prime}(\mathrm{C} 4, \mathrm{C} 5)$ & - & 1.67 \\
\hline
\end{tabular}

\section{Analysis of the CDFT indices of C-cyclopropyl-N-methylnitrone 1 and styrene 2}

The conceptual CDFT indices provides an initial understanding of the reactivity of organic molecules $[14,45,46]$. The CDFT indices were calculated at the B3LYP/6-31G(d) computational level since this level was used to define the electrophilicity and nucleophilicity scales $[47,48]$. The electronic chemical potential, $\mu$, chemical hardness, $\eta$, electrophilicity, $\omega$, and nucleophilicity, $N$, at the ground state of C-cyclopropyl-Nmethylnitrone $\mathbf{1}$ and styrene $\mathbf{2}$ are listed in Table 2.

The electronic chemical potential $\mu$ of $\mathrm{C}$-cyclopropyl-N-methylnitrone $\mathbf{1}, \mu=-3.34 \mathrm{eV}$, is higher than those of styrene $\mathbf{2}$, which is $-3.88 \mathrm{eV}$. The electrophilicity $\omega$ and nucleophilicity $N$ indices of C-cyclopropyl-Nmethylnitrone $\mathbf{1}$ are 1.12 and $3.65 \mathrm{eV}$ respectively, being classified a marginal electrophile and strong nucleophile within the corresponding scales $[47,48]$.

The electrophilicity $\omega$ and nucleophilicity $N$ indices of styrene 2 are 1.49 and $3.09 \mathrm{eV}$ respectively; being is classified as a marginal electrophile and strong nucleophile. Therefore, C-cyclopropyl-N-methylnitrone $\mathbf{1}$ will participate as a nucleophile and styrene $\mathbf{2}$ will participate as an electrophile.

Table 2. The chemical hardness $\eta$, electronic chemical potential $\mu$, global nucleophilicity $N$ and global electrophilicity $\omega$, in $\mathrm{eV}$, of C-cyclopropyl-N-methylnitrone 1 and styrene 2 at B3LYP/6-31G(d) level of theory.

\begin{tabular}{|c|c|c|c|c|}
\hline & $\boldsymbol{\mu}$ & $\boldsymbol{\eta}$ & $\boldsymbol{\omega}$ & $\boldsymbol{N}$ \\
\hline $\mathbf{1}$ & -3.34 & 4.99 & 1.12 & 3.65 \\
\hline $\mathbf{2}$ & -3.88 & 5.04 & 1.49 & 3.09 \\
\hline
\end{tabular}

Analysis of the reaction paths associated with the $32 \mathrm{CA}$ reactions of $\mathrm{C}$-cyclopropyl-Nmethylnitrone 1 and styrene 2

Due to the molecular asymmetry of styrene $\mathbf{2}$, four reaction paths are feasible for these 32CA reactions (see Scheme 1). The search for the stationary points involved in the reaction paths associated to these 32CA reactions allowed characterizing the reactants, $\mathbf{1}$ and $\mathbf{2}$, four TSs for 32CA reaction, TS1-ex, TS1-en, TS2-ex and TS2-en, and the corresponding products 3, 4,5 and 6, respectively, (see Scheme 1). The relative energies and thermodynamic data of TSs and cycloadducts are given in Table 3.

The activation enthalpies associated with these 32CA reactions are TS1-ex, 20.61, TS1-en, 22.35, TS2-ex, 24.51 and TS2-en, $25.37 \mathrm{kcal}^{-\mathrm{mol}^{-1}}$ in the gas phase, and TS1-ex, 22.84, TS1-en, 23.84, TS2-ex, 27.58 and TS2-en, $28.62 \mathrm{kcal}^{-\mathrm{mol}^{-1}}$ in chloroform at $298 \mathrm{~K}$; the reactions being exothermic between 11.94 to 9.82 $\mathrm{kcal} . \mathrm{mol}^{-1}$ in the gas phase, and between 7.72 to $4.56 \mathrm{kcal}^{\mathrm{mol}}{ }^{-1}$ in chloroform.

Analysis of the relative enthalpies allows establishing some appealing conclusions: i) the $32 \mathrm{CA}$ reaction between C-cyclopropyl-N-methylnitrone $\mathbf{1}$ and styrene $\mathbf{2}$ leading the formation of cycloadduct $\mathbf{3}$ presents the lowest activation enthalpy; $20.61 \mathrm{kcal}^{\mathrm{mol}}{ }^{-1}$ in the gas phase and $22.84 \mathrm{kcal}^{\mathrm{mol}}{ }^{-1}$ in chloroform. ii) the activation enthalpy for this 32CA reaction that correspond for the formation of cycloadducts 3 is lowered by about $4 \mathrm{kcal}^{\mathrm{mol}} \mathrm{I}^{-1}$ in both the gas phase and in chloroform. iii) the reaction enthalpy for cycloadduct 3 obtained from the 32CA reaction between C-cyclopropyl-N-methylnitrone $\mathbf{1}$ and styrene $\mathbf{2}$ is lowered than that 
of 5 by about $2 \mathrm{kcal}^{\mathrm{mol}}{ }^{-1}$ in the gas phase and in chloroform. v) These 32CA reactions are endergonic with reactions Gibbs free energies between 2.83 and 7.39 kcalmole-1 in the gas phase. vi) the inclusion of solvent effect of chloroform slightly increases the activation enthalpies and slightly increases the reaction enthalpies.

The B3LYP/6-311++G(d,p) optimized geometries of TSs are given in Fig. 3. In gas phase, the distances between $\mathrm{C} 3$ and $\mathrm{C} 4$, and $\mathrm{O} 1$ and $\mathrm{C} 5$ interacting centers at the transition states are: 2.05 and $2.30 \AA$ at TS1-ex, 2.06 and $2.77 \AA$ at TS1-en, 1.98 and $2.18 \AA$ at 1 TS2-ex and 1.92 and $2.30 \AA$ at TS2-en, respectively. The TSs geometries show similar trend and minimal changes on inclusion of solvent effect in chloroform. Considering that the C-O and C-N bond formation begins at the distances of 1.70-1.79 and 1.90-1.80 respectively, these geometrical parameters indicate that at the at all TSs, the formation of the C-O or C-N single bonds has not yet begun [15]. Similar results were found by Domingo and Ríos-Gutiérrez for the reaction of the 32CA reaction of nitrone and nitrile ylide with ethylene [15].

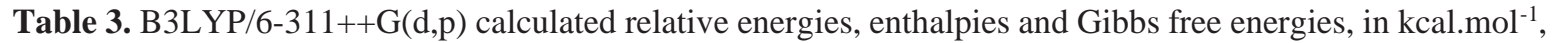
computed at $298 \mathrm{~K}$ of the stationary points involved in the 32CA reactions of C-cyclopropyl-N-methylnitrone 1 and styrene 2.

\begin{tabular}{|c|c|c|c|c|c|c|c|c|}
\hline & \multicolumn{4}{|c|}{ Gas phase } & \multicolumn{4}{c|}{ Chloroform } \\
\hline & $\Delta \mathbf{E}$ & $\Delta \mathbf{H}$ & $\Delta \mathbf{G}$ & GEDT & $\Delta \mathbf{E}$ & $\Delta \mathbf{H}$ & $\Delta \mathbf{G}$ & GEDT \\
\hline TS1-ex & 21.19 & 20.61 & 34.71 & 0.00 & 23.38 & 22.84 & 38.52 & 0.00 \\
\hline $\mathbf{3}$ & -10.90 & -11.94 & 2.83 & - & -6.72 & -7.72 & 8.51 & - \\
\hline TS1-en & 22.87 & 22.35 & 36.29 & 0.01 & 24.21 & 23.84 & 41.32 & 0.01 \\
\hline $\mathbf{4}$ & -10.53 & -11.56 & 3.28 & - & -5.65 & -6.34 & 9.71 & - \\
\hline TS2-ex & 25.15 & 24.51 & 38.93 & 0.01 & 28.15 & 27.58 & 43.38 & 0.01 \\
\hline $\mathbf{5}$ & -8.73 & -9.82 & 5.45 & - & -4.85 & -5.91 & 10.79 & - \\
\hline TS2-en & 26.04 & 25.37 & 40.16 & 0.02 & 29.24 & 28.62 & 45.38 & 0.02 \\
\hline $\mathbf{6}$ & -7.02 & -8.14 & 7.39 & - & -3.15 & -4.56 & 12.84 & - \\
\hline
\end{tabular}

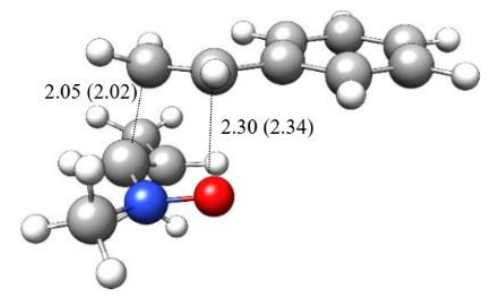

TS1-ex

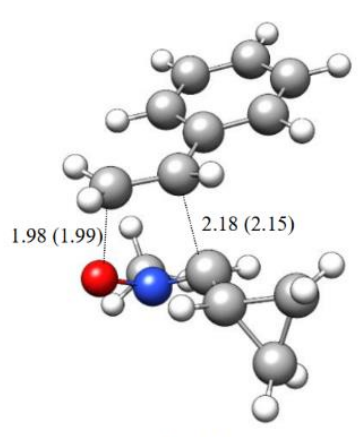

TS2-ex

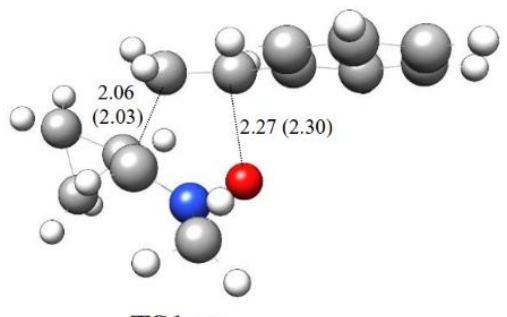

TS1-en

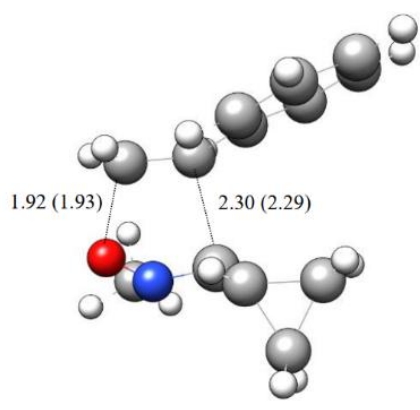

TS2-en

Fig. 3. B3LYP/6-311++G(d,p)optimized geometries of the transition states involved in the 32CA reaction of C-cyclopropyl-N-methylnitrone 1 and styrene 2. Bond lengths are given in Angstroms. The values in parenthesis are calculated in chloroform. 
The polar nature of the 32CA reactions was analyzed by GEDT calculations [32]. The GEDT values in the gas phase at the TSs are 0.001 e at TS1-ex, 0.011 e at TS1-en, 0.011 e at TS2-ex, and 0.020 e at TS2-en (see Table 3). Similar values of GEDT were obtained for all TSs in chloroform as a solvent. The favorable TS1ex with lower activation energies leading to more stable cycloadducts $\mathbf{3}$ show lower GEDT values compared to the other TSs, owing to the dependence of the GEDT on three factors- the nucleophilicity and the electrophilicity of the reagents, and the distance between the two frameworks, the TS1-en, TS2-ex and TS2-en are more energetic and more advanced, which makes the GEDT higher at these TSs [32, 49].

\section{The BET study of the 32CA reactions of C-cyclopropyl-N-methylnitrone 1 and styrene 2}

Herein, a study of the BETs for TS1-ex of the 32CA reactions of C-cyclopropyl-N-methylnitrone 1 and styrene $\mathbf{2}$ is presented. The 32CA reaction of $\mathbf{1}$ with $\mathbf{2}$ takes place along seven different phases (see Table 4) [50]. Phase I corresponds to the starting phase of the IRCs. S0 (see Table 4) at dO1-C5 = 3.21 $\AA$ is the representative IRC points of the phase I for the first path of the reaction. ELF of S0 is similar to that of the separated reagents.

Phase II starts at $\mathrm{S} 1, \mathrm{~d}(\mathrm{O} 1-\mathrm{C} 5)=2.41 \AA$ and $\mathrm{d}(\mathrm{C} 3-\mathrm{C} 4)=2.29 \AA$. S1 shows the formation of $\mathrm{V}(\mathrm{N} 2)$ monosynaptic basin integrating at $1.04 \mathrm{e}$. The electron density for formation of $\mathrm{V}(\mathrm{N} 2)$ monosynaptic basin in $\mathrm{S} 1$ is derived from $\mathrm{V}(\mathrm{N} 2, \mathrm{C} 3)$ disynaptic basin which shows depopulation from 3.88 e in S0 to 2.80 e in $\mathrm{S} 1$. Interestingly, S1 shows GEDT values of 0.039. This suggests increased polar character and hence lower energy requirement to reach $\mathrm{S} 1$.

Table 4. ELF valence basin populations, the GEDT values and distances of the forming bonds of the IRC structures S0-S6 and 3 defining the eight phases characterizing the molecular mechanism of the 32CA reaction of C-cyclopropyl-N-methylnitrone 1 and styrene 2 yielding product 3. Distances, $\mathrm{d}(\mathrm{C} 5-\mathrm{O} 1)$ and $\mathrm{d}(\mathrm{C} 3-\mathrm{C} 4)$, are given in angstroms, $\AA$.

\begin{tabular}{|c|c|c|c|c|c|c|c|c|}
\hline Phases & I & II & III & IV & V & VI & \multicolumn{2}{|c|}{ VIII } \\
\hline Structures & S0 & S1 & $\begin{array}{c}\text { S2=TS1- } \\
\text { ex }\end{array}$ & S3 & S4 & S5 & S6 & $\mathbf{3}$ \\
\hline $\mathrm{d}(\mathrm{C} 5-\mathrm{O} 1)$ & 3.21 & 2.41 & 2.11 & 2.05 & 1.95 & 1.68 & 1.58 & 1.45 \\
\hline $\mathrm{d}(\mathrm{C} 3-\mathrm{C} 4)$ & 3.62 & 2.29 & 2.17 & 2.10 & 1.98 & 1.69 & 1.63 & 1.55 \\
\hline $\mathrm{GEDT}$ & 0.039 & 0.055 & 0.001 & 0.015 & 0.078 & 0.225 & 0.245 & $0.259 .$. \\
\hline $\mathrm{V}(\mathrm{O} 1)$ & 3.03 & 2.98 & 2.93 & 2.92 & 2.90 & 2.76 & 2.66 & 2.83 \\
\hline $\mathrm{V}(\mathrm{O} 1)$ & 2.89 & 2.91 & 2.90 & 2.89 & 2.89 & 2.68 & 2.62 & 2.61 \\
\hline $\mathrm{V}(\mathrm{N} 2, \mathrm{C} 3)$ & 3.88 & 2.80 & 2.32 & 2.16 & 2.04 & 1.95 & 1.90 & 1.86 \\
\hline $\mathrm{V}(\mathrm{N} 2, \mathrm{O} 1)$ & 1.39 & 1.24 & 1.22 & 1.13 & 1.09 & 0.95 & 0.93 & 0.84 \\
\hline $\mathrm{V}(\mathrm{N} 2)$ & & 1.04 & 1.46 & 1.71 & 1.85 & 2.15 & 2.23 & 2.35 \\
\hline $\mathrm{V}(\mathrm{C} 3)$ & & 0.34 & 0.54 & 0.75 & 0.98 & & & \\
\hline $\mathrm{V}(\mathrm{C} 4, \mathrm{C} 5)$ & 1.68 & 1.65 & 1.39 & 2.54 & 2.32 & 2.06 & 1.97 & 1.95 \\
\hline $\mathrm{V}(\mathrm{C} 4, \mathrm{C} 5)$ & 1.67 & 1.64 & 1.36 & & & & & \\
\hline $\mathrm{V}(\mathrm{C} 4)$ & & & 0.37 & 0.85 & 1.24 & & & \\
\hline $\mathrm{V}(\mathrm{C} 5)$ & & & & & 0.22 & 0.69 & & \\
\hline $\mathrm{V}(\mathrm{C} 5, \mathrm{O} 1)$ & & & & & & & 0.96 & 1.14 \\
\hline $\mathrm{V}(\mathrm{C} 3, \mathrm{C} 4)$ & & & & & & 1.75 & 1.82 & 1.86 \\
\hline
\end{tabular}

Phase III starts at $\mathrm{S} 2, \mathrm{~d}(\mathrm{O} 1-\mathrm{C} 5)=2.11 \AA$ and $\mathrm{d}(\mathrm{C} 3-\mathrm{C} 4)=2.17 \AA$, and this shows the formation of $\mathrm{V}(\mathrm{C} 3)$ and $\mathrm{V}(\mathrm{C} 4)$ monosynaptic basins integrating at $0.34 \mathrm{e}$. The electron density demanded for the formation 
of this monosynaptic basin comes from the depopulation of the C4-C5 bonding region, which has been depopulated by about 0.45 e. S2 shows the GEDT value of 0.006. As shown in Fig. 4, TS1-ex belongs to Phase III. This suggests that the relative energies of the TSs correspond to the energy cost for the formation of pseudoradicals centers at the reacting nuclei. This 32CA reaction involves early TS with no new covalent bond formation. Phase IV starts at S3, d $(\mathrm{O} 1-\mathrm{C} 5)=2.05 \AA$ and $\mathrm{d}(\mathrm{C} 3-\mathrm{C} 4)=2.10 \AA$. S3 shows the formation of $\mathrm{V}(\mathrm{C} 4)$ monosynaptic basin integrating at 0.37 , which is formed by deriving electron density from $\mathrm{V}(\mathrm{N} 2, \mathrm{C} 3)$ disynaptic basin and $\mathrm{S} 3$ shows the GEDT value of 0.015 .

Phase V starts at $\mathrm{S} 4, \mathrm{~d}(\mathrm{O} 1-\mathrm{C} 5)=1.95 \AA$ and $\mathrm{d}(\mathrm{C} 3-\mathrm{C} 4)=1.98 \AA$, with the formation of pseudoradical center at C5 integrating at $0.22 \mathrm{e}$. Phase VI starts at S5 for the, dO1-C5 $=1.68 \AA$ and dC3-C4=1.69 $\mathrm{A}$. At this structure, while the $\mathrm{V}(\mathrm{C} 3)$ and $\mathrm{V}(\mathrm{C} 4)$ monosynaptic basin presents at $\mathrm{S} 3$ is missing in S4. At the beginning of this phase the first more relevant change along the IRCs takes place. The first $\mathrm{C} 3$-C4 single bond formation begins at the $\mathrm{C} 3-\mathrm{C} 4$ distance of $1.69 \AA$, characterised by the creation of disynaptic basin $\mathrm{V}(\mathrm{C} 3, \mathrm{C} 4)$ integrating $1.75 \mathrm{e}$.

Finally, the last Phase VII starts at $\mathrm{S} 6, \mathrm{~d}(\mathrm{O} 1-\mathrm{C} 5)=1.58 \AA$ and $\mathrm{d}(\mathrm{C} 3-\mathrm{C} 4)=1.63 \AA$, the second more relevant change along the IRC takes place. At these structures, a new $\mathrm{V}(\mathrm{O} 1, \mathrm{C} 5)$ disynaptic basin is created integrating $0.96 \mathrm{e}$, while the $\mathrm{V}(\mathrm{C} 5)$ monosynaptic basins is disappeared. This relevant topological change indicates that the formation of the second O1-C5 single bond has started, through the C- to -O coupling of the electron density of the C5 pseudoradical carbon and part of the non-bonding electron density of the $\mathrm{O} 1$ oxygen lone pairs. The molecular electron density, along this phase, is relaxed to reach the structure of product 3 in the $32 \mathrm{CA}$ reaction, in which the population of the $\mathrm{V}(\mathrm{C} 3, \mathrm{C} 4)$ and $\mathrm{V}(\mathrm{O} 1, \mathrm{C} 5)$ disynaptic basins reach a population of $1.86 \mathrm{e}$ and $1.14 \mathrm{e}$, respectively.

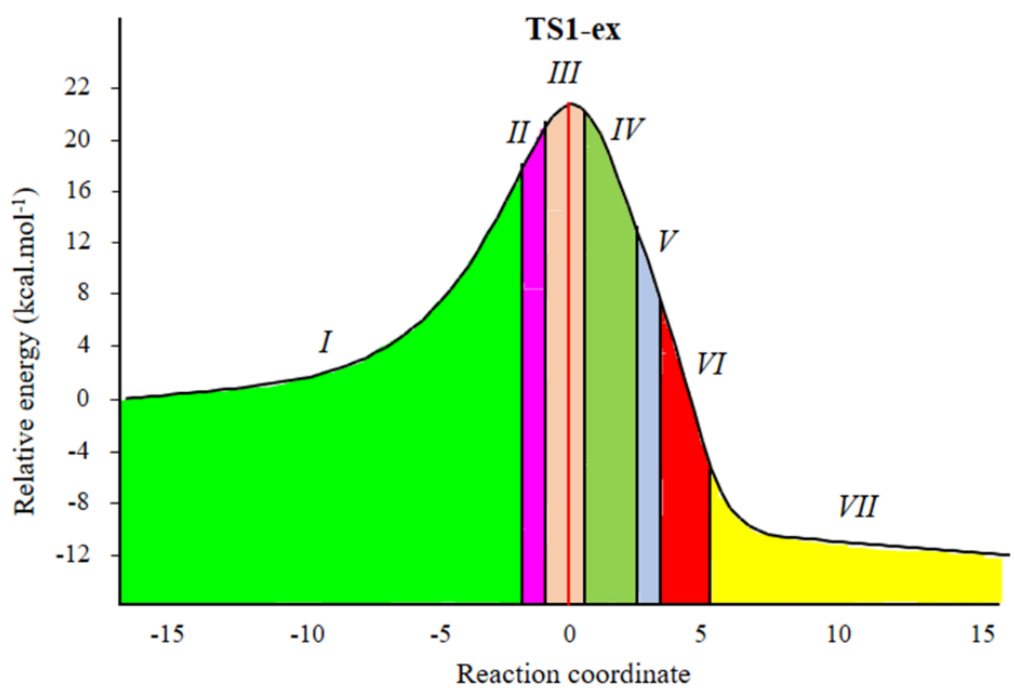

Fig. 4. ELF topological phases for [3+2] cycloaddition reactions of C-cyclopropyl-N-methylnitrone 1 and styrene 2 . The red line indicates the position of TS1, the phases are shown as colored regions defined by points along the IRC.

\section{ELF Topological analysis of at TS1-ex, TS1-en, TS2-ex and TS2-en}

The ELF topological analysis of TS1-ex, TS1-en, TS2-ex and TS2-en were analyzed and compared. Table 5 shows the populations of the most significant valence basin at TS1-ex, TS1-en, TS2-ex and TS2-en, whereas Fig. 5 represents the ELF localization domains. ELF of the four TSs shows the presence of two monosynaptic basins, $\mathrm{V}(\mathrm{O} 1)$ and $\mathrm{V}^{\prime}(\mathrm{O} 1)$, which are associated with the non-bonding electron densities at the O1 oxygen, already present in C-cyclopropyl-N-methylnitrone $\mathbf{1}$ and styrene $\mathbf{2}$ (see Tables 1 and 4). 
ELF topological analysis of TS1-ex, TS1-en, TS2-ex and TS2-en also displays the presence of single $\mathrm{V}(\mathrm{N} 2)$ monosynaptic basin, integrating 1.46- $1.59 \mathrm{e}$, which comes from the depopulation of the N2-C3 bonding region. The N2-C3 bonding region undergoes a depopulation of the electron density from $3.88 \mathrm{e}$ in $\mathbf{1}$ to $2.32 \mathrm{e}$, $2.31 \mathrm{e}, 2.34 \mathrm{e}$ and $2.34 \mathrm{e}$ in TS1-ex, TS1-en, TS2-ex and TS2-en, respectively.

At the styrene framework, a disynaptic basin, $\mathrm{V}(\mathrm{C} 4, \mathrm{C} 5)$, associated with $\mathrm{C} 4-\mathrm{C} 5$ bonding region integrating a total population of 2.75 e (TS1-ex), 2.75 (TS1-en), 2.76 e (TS2-ex) and 2.77 e (TS2-en) is observed. The ELF of transition states show the presence of single $\mathrm{V}(\mathrm{C} 4)$ monosynaptic basin integrating at 0.37 e, 0.40 e, 0.40 e and 0.39 e for TS1-ex, TS1-en, TS2-ex and TS2-en, respectively, and single V(C3) monosynaptic basin is also observed for TS1-ex, TS1-en, TS2-ex and TS2-en integrating at $0.54 \mathrm{e}, 0.55 \mathrm{e}, 0.47$ e and 0.44 e, respectively. The $\mathrm{V}(\mathrm{O} 1, \mathrm{C} 5)$ and $\mathrm{V}(\mathrm{C} 3, \mathrm{C} 4)$ disynaptic basin at TS1 and TS2 are not appeared, which indicates that the formation of $\mathrm{O} 1-\mathrm{C} 5$ and $\mathrm{C} 3-\mathrm{C} 4$ single bonds has not yet started.

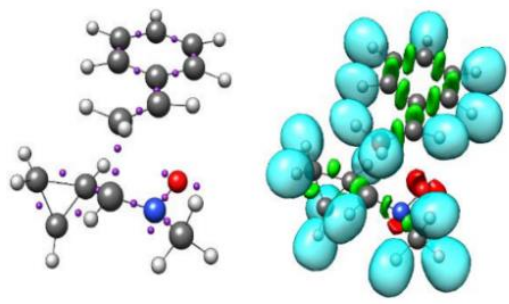

TS1-ex
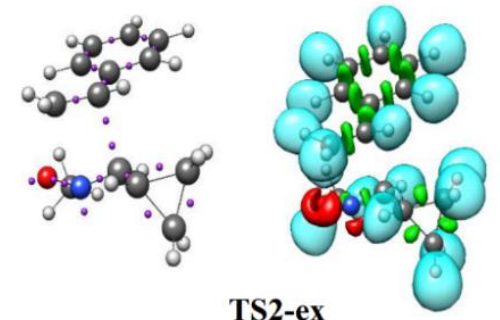
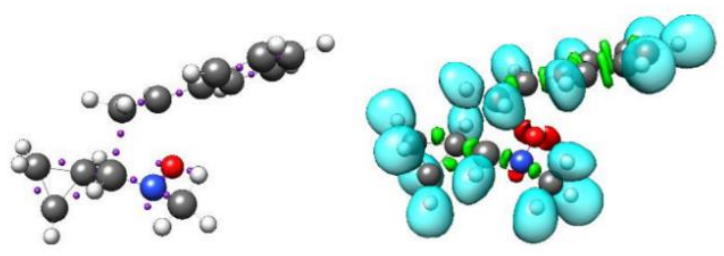

TS1-en

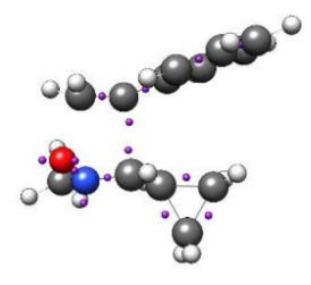

TS2-en

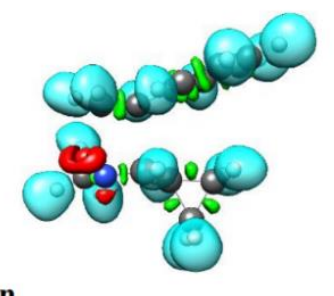

Fig. 5. Pictorial representation of B3LYP/6-311++G(d,p) ELF localization domains of TS1-ex, TS1-en, TS2ex and TS2-en represented at an isosurface value of $E L F=0.85$. Monosynaptic basins are shown in red, disynaptic basins are shown in green and protonated basins are shown in blue. The attractors are shown in violet color.

Table 5. B3LYP/6-311++G(d,p) calculated most significant ELF valence basin populations at the TSs.

\begin{tabular}{|c|c|c|c|c|}
\hline & TS1-ex & TS1-en & TS2-ex & TS2-en \\
\hline $\mathrm{V}(\mathrm{O} 1)$ & 2.93 & 2.95 & 2.91 & 2.91 \\
\hline $\mathrm{V}^{\prime}(\mathrm{O} 1)$ & 2.90 & 2.87 & 2.90 & 2.89 \\
\hline $\mathrm{V}(\mathrm{N} 2)$ & 1.46 & 1.44 & 1.56 & 1.59 \\
\hline $\mathrm{V}(\mathrm{N} 2, \mathrm{O} 1)$ & 1.22 & 1.22 & 1.15 & 1.16 \\
\hline $\mathrm{V}(\mathrm{N} 2, \mathrm{C} 3)$ & 2.32 & 2.31 & 2.34 & 2.34 \\
\hline $\mathrm{V}(\mathrm{C} 4, \mathrm{C} 5)$ & 2.75 & 2.75 & 2.76 & 2.77 \\
\hline $\mathrm{V}(\mathrm{C} 3)$ & 0.54 & 0.55 & 0.47 & 0.44 \\
\hline $\mathrm{V}(\mathrm{C} 4)$ & 0.37 & 0.40 & 0.40 & 0.39 \\
\hline
\end{tabular}




\section{Conclusion}

The 32CA reactions of C-cyclopropyl-N-methylnitrone $\mathbf{1}$ and styrene $\mathbf{2}$ has been studied within MEDT at the B3LYP/6-311++G(d,p) level of theory. The ELF topological analysis of C-cyclopropyl-N-methylnitrone 1 clearly indicates that this TAC participate in zw-type 32CA. The 32CA reactions of C-cyclopropyl-Nmethylnitrone 1 and styrene $\mathbf{2}$ takes place through a one-step mechanism. The global electronic flux from the nitrone $\mathbf{1}$ to the styrene $\mathbf{2}$ is predicted, owing to the high electronic chemical potential and strong nucleophilicity of the nitrone 1 relative to the styrene 2. These 32CA reactions are endergonic with positive free energy of reaction. The activation enthalpy for 32CA reaction leading for the formation of product $\mathbf{3}$ is lower than the other paths. Analysis of the geometrical parameters indicates that at all TSs, the formation of the C-O or C-N single bonds has not yet begun.

The BET analysis of the 32CA reactions of C-cyclopropyl-N-methylnitrone $\mathbf{1}$ and styrene 2 leading to the formation of $\mathbf{3}$ shows the formation of $\mathrm{N} 2$ non-bonding electron density regions at the beginning of the reaction with the GEDT of $0.051 \mathrm{e}$. Consequently, increase in GEDT accounts for the lowering of energy cost along the reaction paths. The present MEDT study allows concluding that the higher acceleration for the $z w$ type 32CA reaction of C-cyclopropyl-N-methylnitrone $\mathbf{1}$ and styrene $\mathbf{2}$ passing through TS1-ex is a consequence of the regioselectivity of this $32 \mathrm{CA}$ reaction.

\section{Acknowledgments}

I would like to acknowledge the Department of Chemistry in University of Zakho and Department of Chemistry in Salahaddin University.

\section{References}

1. Mohammad-Salim, H. A.; Abdallah, H. H.; Maiyelvaganan, K. R.; Prakash, M.; Hochlaf, M. Theor. Chem. Acc. 2020, 139, 19. DOI: https://doi.org/10.1007/s00214-019-2542-y

2. Mohammad-Salim, H. A.; Abdallah, H. H. ARO 2019, 7, 9. DOI: https://doi.org/10.14500/aro.10575

3. Mohammad Salim, H.; Abdallah, H. Oriental J. Chem. 2019, 35, 1550-1556. DOI: https://doi.org/10.13005/ojc/350512

4. Salim, H. A. M.; Abdallah, H. H.; Ramasami, P. IOP Conf. Ser.: Mater. Sci. Eng. 2018, 454, 012049. DOI: https://doi.org/10.1088/1757-899x/454/1/012049

5. Salim, H. M.; Abdallah, H. H.; Ramasami, P. 2018 International Conference on Advanced Science and Engineering (ICOASE), 9-11 Oct. 2018; 2018; pp 415-419. DOI: https://doi.org/10.1109/ICOASE.2018.8548917

6. Lauria, A.; Delisi, R.; Mingoia, F.; Terenzi, A.; Martorana, A.; Barone, G.; Almerico, A. M. Eur. J. Org. Chem. 2014, 2014, 3289-3306. DOI: https://doi.org/10.1002/ejoc.201301695

7. Li, Q.-H.; Wei, L.; Wang, C.-J. J. Am. Chem. Soc. 2014, 136, 8685-8692. DOI: https://doi.org/10.1021/ja503309u

8. Shevelev, S.; Starosotnikov, A. Chem. Heterocycl. Compd. 2013, 49, 92-115. DOI: https://doi.org/10.1007/s10593-013-1233-1

9. Mohammad-Salim, H.; Hassan, R.; Abdallah, H. H.; Oftadeh, M. J. Mex. Chem. Soc. 2020, 64. DOI: https://doi.org/10.29356/jmcs.v64i2.1111

10. Anderson, L. L. Asian J. Org. Chem. 2016, 5, 9-30. DOI: https://doi.org/10.1002/ajoc.201500211

11. Ríos-Gutiérrez, M.; Darù, A.; Tejero, T.; Domingo, L. R.; Merino, P. Org. Biomol. Chem. 2017, 15, 1618-1627. DOI: https://doi.org/10.1039/C6OB02768G

12. Frederickson, M. Tetrahedron 1997, 53, 403-425. DOI: https://doi.org/10.1016/S00404020(96)01095-2 
13. Wanapun, D.; Van Gorp, K.; Mosey, N.; Kerr, M.; Woo, T. Can. J. Chem. 2005, 83, 1752-1767. DOI: https://doi.org/10.1139/v05-182

14. Domingo, L. R. Molecules 2016, 21, 1319. DOI: https://doi.org/10.3390/molecules 21101319

15. Rios-Gutiérrez, M.; Domingo, L. Eur. J. Org. Chem 2019, 267. DOI: https://doi.org/10.1002/ejoc.201800916

16. Abbiche, K.; Mohammad-Salim, H.; Salah, M.; Mazoir, N.; Zeroual, A.; El Alaoui El Abdallaoui, H.; El Hammadi, A.; Hilali, M.; Abdallah, H. H.; Hochlaf, M. Theor. Chem. Acc. 2020, 139, 148. DOI: https://doi.org/10.1007/s00214-020-02662-4

17. Domingo, L. R.; Acharjee, N.; Mohammad-Salim, H. A. Organics 2020, 1, 3-18. DOI: https://doi.org/10.3390/org1010002

18. Mohammad-Salim, H. A.; Acharjee, N.; Domingo, L. R.; Abdallah, H. H. Int. J. Quantum Chem. 2020, e26503. DOI: https://doi.org/10.1002/qua.26503

19. Jasiński, R.; Jasińska, E.; Dresler, E. J. Mol. Model. 2016, 23, 1-9. DOI: https://doi.org/10.1007/s00894-016-3185-8

20. Domingo, L. R.; Ríos-Gutiérrez, M.; Pérez, P. Org. Biomol. Chem. 2016, 14, 10427-10436. DOI: https://doi.org/10.1039/C6OB01989G

21. Domingo, L. R.; Aurell, M. J.; Pérez, P. Tetrahedron 2015, 71, 1050-1057. DOI: https://doi.org/10.1016/j.tet.2014.12.094

22. Domingo, L. R.; Aurell, M. J.; Pérez, P. Tetrahedron 2014, 70, 4519-4525. DOI: https://doi.org/10.1016/j.tet.2014.05.003

23. Bimanand, A. Z.; Houk, K. N. Tetrahedron Lett. 1983, 24, 435-438. DOI: https://doi.org/10.1016/S0040-4039(00)81429-X

24. Frisch, M.; Trucks, G.; Schlegel, H.; Scuseria, G.; Robb, M.; Cheeseman, J.; Scalmani, G.; Barone, V.; Petersson, G.; Nakatsuji, H., Gaussian 16. Revision A 2016, 3.

25. Parr, R. G.; Weitao, Y., Density-Functional Theory of Atoms and Molecules. Oxford University Press: 1989.

26. Khabashesku, V. N.; Kudin, K. N.; Margrave, J. L. Russ. Chem. Bull. 2001, 50, 20-28. DOI: https://doi.org/10.1023/A:1009508730904

27. Lemal, D. M. J. Org. Chem. 2017, 82, 13012-13019. DOI: https://doi.org/10.1021/acs.joc.7b01911

28. Ditchfield, R.; Hehre, W. J.; Pople, J. A. 1971, 54 , 724-728. DOI: https://doi.org/10.1063/1.1674902

29. Lee, C.; Yang, W.; Parr, R. G. Phys. Rev. B 1988, 37, 785-789. DOI: https://doi.org/10.1103/PhysRevB.37.785

30. Barone, V.; Cossi, M. J. Phys. Chem. A 1998, 102, 1995-2001. DOI: https://doi.org/10.1021/jp9716997

31. Fukui, K. J. Phys. Chem. 1970, 74, 4161-4163. DOI: https://doi.org/10.1021/j100717a029

32. Domingo, L. R. RSC Adv. 2014, 4, 32415-32428. DOI: https://doi.org/10.1039/C4RA04280H

33. Pettersen, E. F.; Goddard, T. D.; Huang, C. C.; Couch, G. S.; Greenblatt, D. M.; Meng, E. C.; Ferrin, T. E. J. Comput. Chem. 2004, 25, 1605-1612. DOI: https://doi.org/10.1002/jcc.20084

34.Parr, R. G.; Pearson, R. G. J. Am. Chem. Soc. 1983, 105, 7512-7516. DOI: https://doi.org/10.1021/ja00364a005

35. Parr, R. G.; Weitao, Y., Density-Functional Theory of Atoms and Molecules. Oxford University Press: 1994.

36. Parr, R. G.; Szentpály, L. v.; Liu, S. J. Am. Chem. Soc. 1999, 121, 1922-1924. DOI: https://doi.org/10.1021/ja983494x

37. Kohn, W.; Sham, L. J. Phys. Rev. 1965, 140, A1133-A1138. DOI: https://doi.org/10.1103/PhysRev.140.A1133

38. Domingo, L. R.; Chamorro, E.; Pérez, P. J. Org. Chem. 2008, 73, 4615-4624. DOI: https://doi.org/10.1021/jo800572a

39. Becke, A. D.; Edgecombe, K. E. J. Chem. Phys. 1990, 92, 5397-5403. DOI: https://doi.org/10.1063/1.458517

40. Silvi, B.; Savin, A. Nature 1994, 371, 683-686. DOI: https://doi.org/10.1038/371683a0

41. Ríos-Gutiérrez, M.; Domingo, L. R. Eur. J. Org. Chem. 2019, 267-282. DOI: https://doi.org/10.1002/ejoc.201800916 
42. Domingo, L. R.; Acharjee, N. ChemistrySelect 2018, 3, 8373-8380. DOI: https://doi.org/10.1002/slct.201801528

43. Acharjee, N.; Banerji, A. J. Chem. Sci. 2020, 132, 65. DOI: https://doi.org/10.1007/s12039-02001766-5

44. Domingo, L. R.; Ríos-Gutiérrez, M.; Pérez, P. J. Org. Chem. 2018, 83, 2182-2197. DOI: https://doi.org/10.1021/acs.joc.7b03093

45. Domingo, L. R.; Ríos-Gutiérrez, M.; Pérez, P. Molecules 2016, 21, $748 . \quad$ DOI: https://doi.org/10.3390/molecules 21060748

46. Geerlings, P.; De Proft, F.; Langenaeker, W. Chem. Rev. 2003, 103, 1793-1874. DOI: https://doi.org/10.1021/cr990029p

47. Domingo, L. R.; Aurell, M. J.; Pérez, P.; Contreras, R. Tetrahedron 2002, 58, 4417-4423. DOI: https://doi.org/10.1016/S0040-4020(02)00410-6

48. Domingo, L. R.; Pérez, P. Org. Biomol. Chem. 2011, 9, 7168-7175. DOI: https://doi.org/10.1039/C1OB05856H

49. Domingo, L. R.; Ríos-Gutiérrez, M.; Pérez, P. Molecules 2020, 25, 2535. DOI: https://doi.org/10.3390/molecules25112535

50. Krokidis, X.; Noury, S.; Silvi, B. J. Phys. Chem. A 1997, 101, 7277-7282. DOI: https://doi.org/10.1021/jp9711508 